\title{
Antenatal diagnosis of idiopathic infantile arterial calcification (IIAC): a single centre experience and review of the literature
}

\author{
C. H. Mulcahy ${ }^{1 *}$, F. Mone ${ }^{1,2}$, F. M. McAuliffe ${ }^{1,2}$, E. Mooney ${ }^{2,3}$, P. McParland ${ }^{1,2}$ and C. J. Mc Mahon ${ }^{4}$
}

\begin{abstract}
Background: Idiopathic infantile arterial calcification (IIAC) is a rare autosomal recessive disorder characterised by extensive calcification and proliferation of the intimal layer of the large and medium size arteries.

Case presentation: We report 4 antenatal cases of IIAC in our institution over a 10 year period from 2006 to 2016. Clinical outcomes, prenatal ultrasound findings, radiological and postmortem investigations are summarized. A literature review of this rare autosomal recessive disease is presented. The possible aetiology of this condition and the role of biphosphonates in the management of this condition are discussed.

Conclusions: This case series highlights the frequent poor outcome of IAC, consistent with the literature, the phenotypical variability of the disease even within the same family and the role of biphosphonates in one prenatally diagnosed case. Hyperechogenicity of the fetal vasculature detected on prenatal ultrasound particularly if there is a history of IIC in an index pregnancy may aid earlier prenatal diagnosis. A multidisciplinary approach to parental counselling can then occur in order to optimise a plan of care in the neonatal period.
\end{abstract}

Keywords: Idiopathic infantile arterial calcification, Generalized arterial calcification of infancy, Arterial calcification, Prenatal diagnosis, Fetal echocardiography

\section{Background}

Idiopathic infantile arterial calcification (IIAC) is an autosomal recessive condition associated with premature onset of arterial calcification and intimal proliferation secondary to unregulated hydroxyapatite deposition leading to vascular stenoses [1]. Other terms to describe the same condition include arterial calcification of infancy, generalized infantile arterial calcification (GACI), idiopathic arterial calcification of infancy (IACI), occlusive infantile arterial calcification and occlusive infantile arteriopathy. Mutations in the ENPP1 gene are associated with IIAC in approx $75 \%$ of patients [2] which lead to decreased levels of inorganic pyrophosphate which is an inhibitor of hydroxyapatite crystal deposition in the vessel wall [3]. Circa just over 200 cases of IIAC have been reported to date since the condition was first described in 1901 by Bryant and White [4]; most of which

\footnotetext{
* Correspondence: cmulcahy@nmh.ie

${ }^{1}$ Fetal Medicine Unit, National Maternity Hospital, Holles St, D2, Dublin, Ireland

Full list of author information is available at the end of the article
}

have been diagnosed in the postnatal period or at autopsy. $85 \%$ of liveborn infants with IIAC die within the first 6 months of life. The majority of prenatally diagnosed cases described to date die in utero or within 5 months of birth $[5,6]$. Calcification of the coronary arteries is a poor prognostic feature and is estimated to occur in $85 \%$ of cases [7] leading to cardiac ischaemia, myocardial infarction and ultimately death in the majority of cases due to heart failure. We present 4 prenatally diagnosed cases in our institution over a ten year period from 2006 to 2016. The role of prenatal biphosphonate treatment in one prenatally diagnosed case with successful outcome is discussed.

\section{Case presentations}

\section{Case 1}

A 21 year old primiparous lady presented for her anatomy scan at $20+1$ weeks gestation. This revealed marked echogenicity of the tricuspid valve and aortic and pulmonary vessels. There was normal ventricular function with no evidence of hydrops or effusion. At $27+4$ weeks gestation 
there was severe biventricular dysfunction with marked calcification of the entire descending aorta since the previous scan. A moderate to large circumferential pericardial effusion of 8-10 mm was evident (Figs. 1 and 2). Polyhydramnios was also present with absent end diastolic flow on umbilical artery doppler and evidence of cerebral redistribution on middle cerebral artery Doppler. An uncomplicated amniocentesis was performed at 28 weeks gestation after consultation with the geneticist to obtain DNA for storage to look for mutations in the ectonucleotide pyrophosphatase /phosphodiesterase 1 (ENPP1) gene known to be responsible for this autosomal recessive condition with a view to future prenatal testing in a future pregnancy. Fetal demise was confirmed at $29+4$ weeks gestation. The diagnosis of IIAC was confirmed from cultured amniocytes from fetal tissue. On post mortem the aorta demonstrated marked calcification. There was also calcification of the branch pulmonary arteries and both atrioventricular valve rings. Calcification was seen in the coronary arteries with secondary (post ischaemic) calcification subendocardially (Fig. 3). Postmortem x-ray showed calcification along the length of the abdominal aorta, the iliac and proximal femoral vessels and also faint calcification of the axillary and subclavian vessels. The compound heterozygous mutation in the ENPP1 gene confirmed the molecular diagnosis postmortem.

\section{Case 2}

A 35 year old woman with a history of a previous fetus affected with IIAC was referred for chorionic villus sampling (CVS) from a peripheral hospital. This first child was born in a peripheral hospital at 34 weeks with hydrops and died of IIAC at 2 days of age. Her CVS result at $12+5$ weeks gestation indicated that the fetus

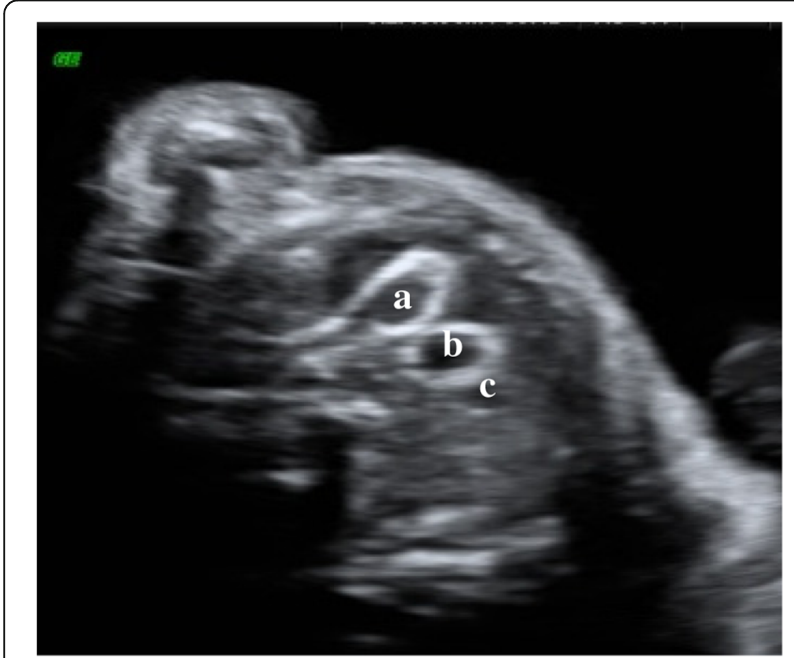

Fig. 1 Calcification of the aorta and pulmonary artery on 3 vessel view at 27 weeks a, Aorta. b, Pulmonary artery c-Superior Vena Cava

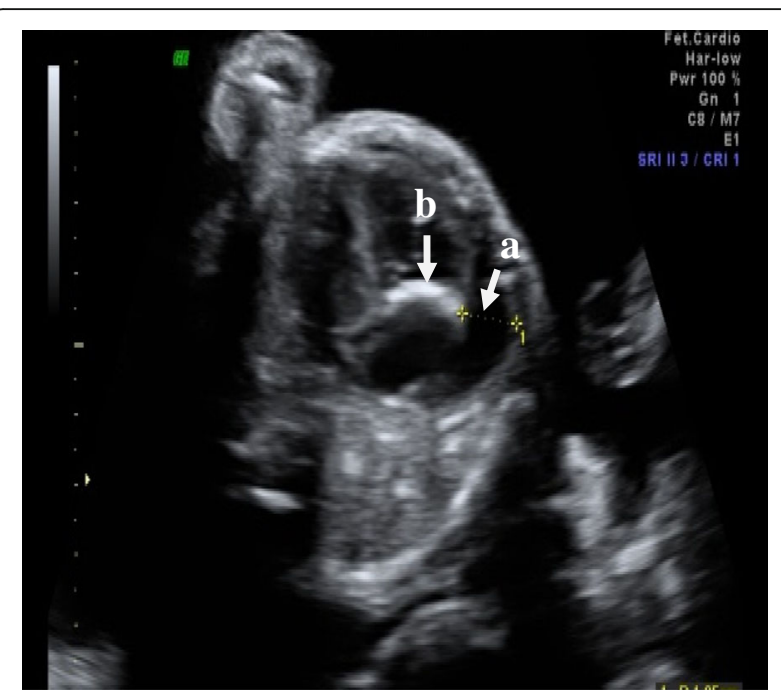

Fig. 2 a, Pericardial effusion and b, calcified tricuspid valve at 27 weeks

was a homozygous carrier for the mutation c. $913 \mathrm{C}>\mathrm{A}$ (p.P305T) in exon 8 of the ENPP1 gene which has been previously identified from the 1st child. Both parents were found to be carriers. While awaiting inclusion in a preimplantation genetic diagnosis programme an unplanned spontaneous conception occurred. At 21 weeks subtle increased echogenicity of the ascending aortic wall was noted. Intrauterine treatment was started with biphosphonates (Etidronate 600mgs BD) from 24 weeks. This remained mild on serial echoes throughout gestation (Fig. 4). The infant at 5 months of age had severe hypophosphataemic rickets which responded to phosphate supplementation and alpha calcidiol. The GACI appears to have not progressed on serial echoes up to 27 months of age. She is asymptomatic and thriving and the rickets have improved.

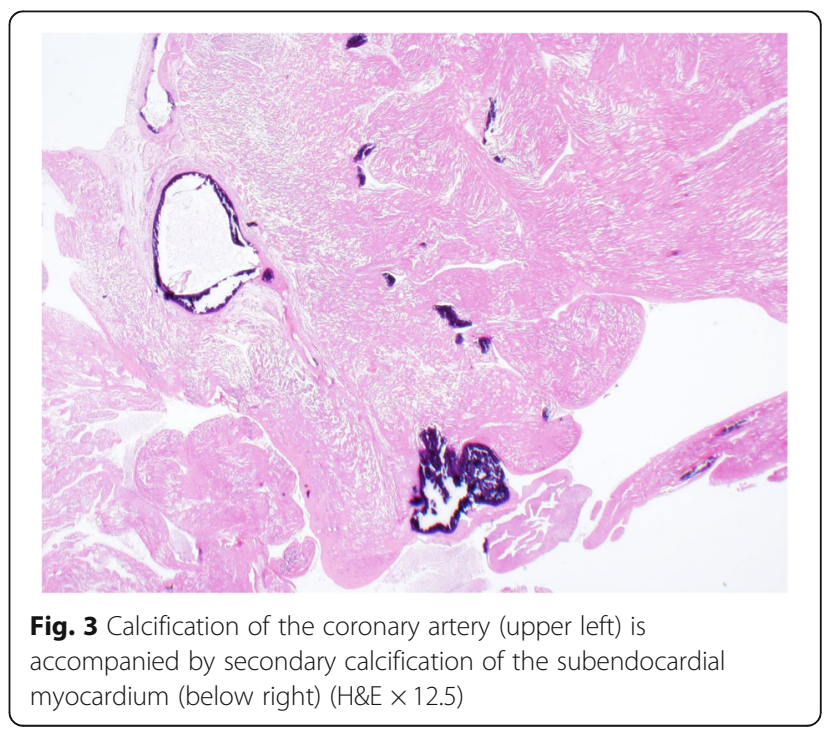




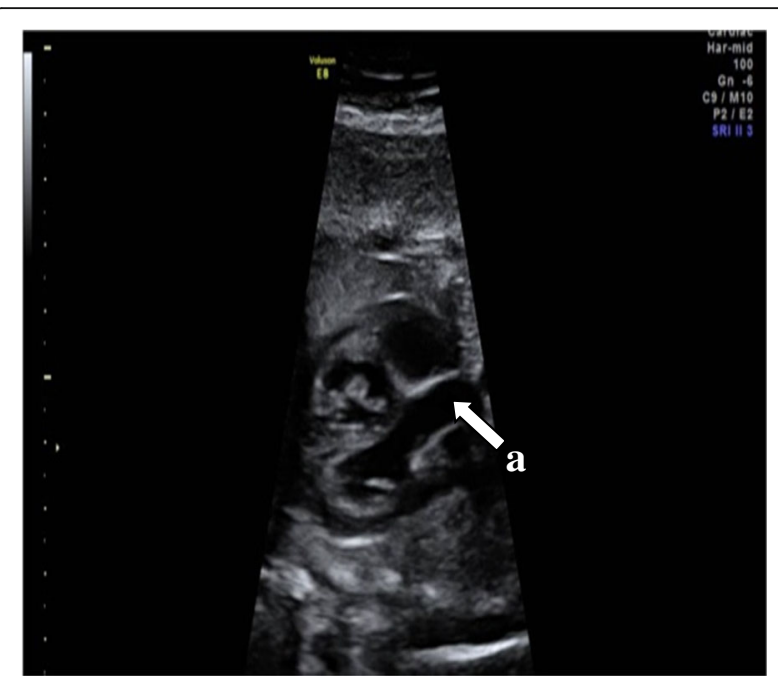

Fig. 4 a, Subtle increased echogenicity of the ascending Aorta at $33+5$ weeks gestation

\section{Case 3}

A 32 year old multiparous lady was referred from a peripheral centre at $31+2$ weeks gestation with fetal cardiomegaly, pericardial effusion and marked calcification of the aorta (Fig. 5), and pulmonary artery and branch pulmonary arteries. A diagnosis of IIAC was made based on ultrasound findings. An uncomplicated amniocentesis was performed showing a normal male karotype. Unfortunately in this case samples were not sent to an external laboratory to look for the ENPP 1 mutation. At $33+1$ weeks gestation there was moderate biventricular hypertrophy and biventricular dysfunction. There was now severe calcification of the aorta and the branch pulmonary arteries and main pulmonary artery. A small circumferential pericardial effusion was noted measuring 3-5 mm. She presented with an intrauterine death at 36 weeks. Postmortem was declined.

\section{Case 4}

A 43 year old multiparous lady was referred from a peripheral hospital at $28+3$ weeks gestation with hydrops and gross polyhydramnios. An amnioreduction (3 L) was performed followed by an abruption and intrauterine death. Amniocentesis revealed a normal female karotype. Further testing for the ENPP 1 mutation was not available at this time. Post-mortem results showed non immune hydrops with vascular calcification of the ascending, thoracic and descending aorta, iliacs, superior mesenteric artery, pulmonary arteries, renal arteries and arteries of the brain (Fig. 6) and tongue. In addition there was cardiomegaly and hepatomegaly with focal calcification. No calcification of placental vasculature was evident. Ischaemic changes of multiple organs were noted. A presumed diagnosis of IIAC was made on postmortem findings.

\section{Discussion}

The last systematic review by Mastrolia et al. in 2015 [5] summarized 23 prenatally diagnosed cases [8-24] of IIAC including two from their own institution. Our review has revealed an additional seven since then [25-31]. To the best of our knowledge there are two reports of similarly early prenatal detection of IIAC in the second trimester without hydrops before 24 weeks as in both our first two cases. The earliest reported case following an extensive review of the literature was in the recipient fetus of a set of monochorionic diamniotic twins affected by twin to twin transfusion syndrome at $18+4$ weeks gestation [25]. Fetal ultrasound revealed hepatic hyperechogenicity consistent with hepatic vascular calcification which became more progressive eventually resulting in hydrops and preterm delivery at 28 weeks. The donor fetus had a pericardial effusion at 25 weeks. The recipient twin was found to have calcification of the deep cerebral arteries, thoracoabdominal aorta, main pulmonary artery and coronary arteries

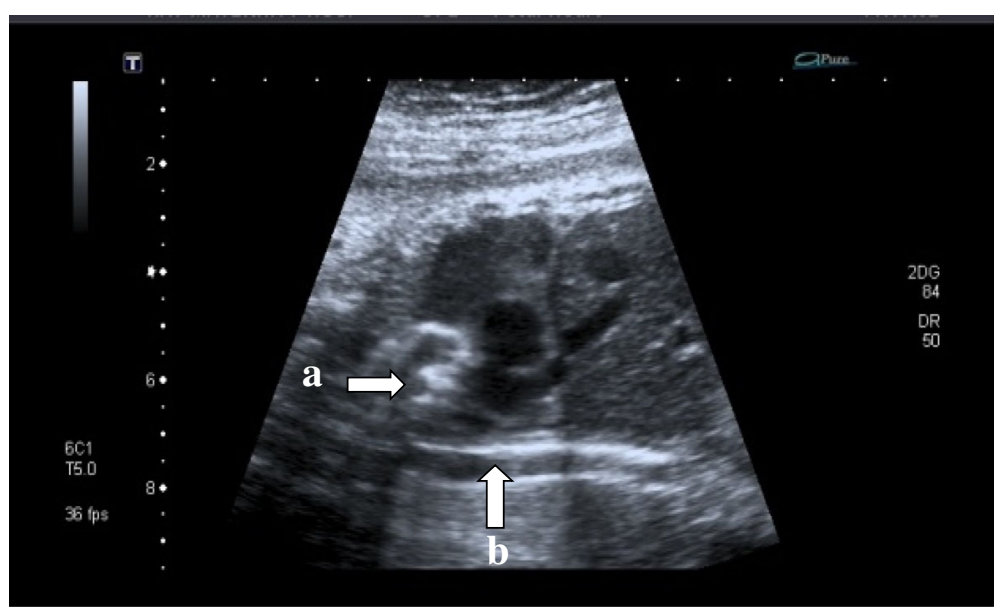

Fig. 5 Marked calcification of the a, ascending Aorta and b, descending aorta 


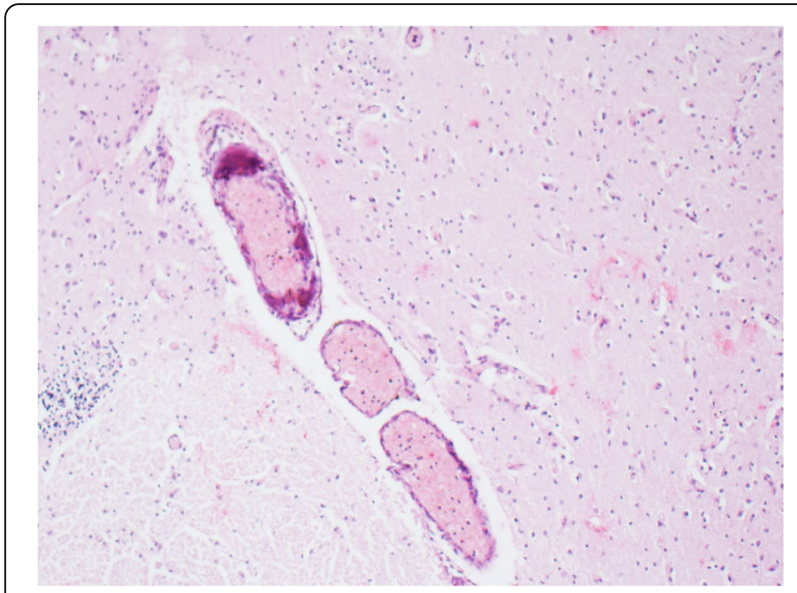

Fig. 6 Calcification is seen in the wall of the artery in the basal ganglia $(H \& E \times 40)$

and hepatic vasculature. The donor twin was found to have aortic and pulmonary arterial calcification. In the second reported case a fetal anatomy scan at 20 weeks revealed an echogenic intracardiac focus and echogenicity of the mitral valve leaflet [9]. This progressed to calcification of the aorta, common iliac arterial and inferior vena caval walls and polyhydramnios developed. The fetus was delivered at 32 weeks because of hydrops and died on day 3 of life. In a subsequent pregnancy a scan at 23 weeks revealed hyperechogenicity of the wall of the fetal aorta and common iliac arteries. This progressed to hydrops and intrauterine demise at 31 weeks gestation. There are only two previously reported cases of early prenatal detection of calcification of the mitral and tricuspid valve $[9,10]$ as in our first case.

Few articles have reported cerebral artery involvement as in our fourth case and in the recipient twin described above [25]. Calcification of the cerebral arteries has been described in four cases [32-35], the earliest reported case in 1948 [33]. Glatz et al. 2006 [3] described a case of rare focal parenchymal microcalcifications in the area of the corpus striatum, internal capsule and choroid plexus on postmortem. Jones et al. 1972 [34] reported calcific change in the cerebral and coronary arteries on postmortem of a grossly hydropic infant and diffuse opacification of the Circle of Willis on postmortem $\mathrm{x}$ - rays. Juul et al. 1990 [35] reported calcification of the basal ganglia on postmortem in two of three siblings diagnosed with IIAC with pituitary involvement in one of the three, which has never been described before.

It is postulated that biphosphonates promote resolution of calcifications but fail to alleviate the myointimal proliferation that the leads to vascular stenosis and organ ischaemia and ultimately organ death [36]. The cases discussed here highlight the phenotypic variation of this condition even within the same family leading some authors [32] to speculate that there are different types of IIAC depending on the degree of myointimal thickening; those with mainly myointimal proliferation being more likely to experience infarction of the heart, kidneys and spleen whereas those with calcification and little intimal thickening experiencing longer survival and even spontaneous regression.

In a retrospective cohort study by Rutsch et al. 2008 [2] biphosphonate therapy was associated with survival in $11(65 \%)$ of 17 treated patients whereas $69 \%$ of the patients not treated with biphosphonates died. Only 8 (31\%) of 26 patients who survived the first day of life and were not treated with biphosphonates survived beyond infancy. However they do acknowledge that the clinical phenotype of the untreated group was probably more severe than the treated group and that hyperphosphatemia and hyperphosphaturia are more likely to be associated with survival beyond infancy. Subjects who died were also more likely to have pulmonary, renal and coronary artery involvement.

ENPP 1 regulates inorganic pyrophosphate (PPi). PPi inhibits extracellular matrix calcification. A subset of those that survive develop hypophosphatemic rickets as in our second case. Hypophosphataemia and hypophosphaturia have been associated with increased survival in such patients. However, later investigators found that the ENPP1 gene mutation was also associated with autosomal recessive hypophosphatemic rickets type 2 (ARHR 2) [37]. To the best of our knowledge there are reports in the literature of 11 long term survivors (greater than or equal to 2 yrs. of age) [7, 38-42]; 4 of these 11 were treated with biphosphonates; of this subgroup the longest surviving adult was reported in 2006 to be 25 years of age [41]. In this case a sibling had died of IIAC. Despite a normal physical examination after delivery in view of the siblings history this infant underwent investigations. X-rays revealed calcification of the carotid, radial, femoral and dorsalis pedis arteries and abdominal aorta and ligamentous calcification of the shoulder. It is thought that resolution of calcification occurs between four months and two years of therapy. However in this case after only 2.5 weeks of etidronate therapy all calcifications had disappeared. As in our second case it is difficult to ascertain if this resolution of calcification represents a milder phenotype of the disease with spontaneous improvement or whether to resolution is due to the biphosphonate therapy. Stuart et al. [8] report two siblings who died despite Etidronate treatment. However one of these two cases presented as a fetal case and both had extensive calcification at the commencement of treatment. Votava-Smith et al. [28] reported a case of arterial calcification in a recipient fetus of monochorionic twins after successful laser treatment for twin to twin transfusion syndrome. Both twins were diagnosed with a 
heterozygous ABCC6 gene mutation associated with GACI. The recipient fetus was started on Etidronate and underwent surgery at four months of age to augment the stenosed main and branch pulmonary arteries and ascending aorta. The infant remained well on Etidronate therapy at 18 months of age. The donor twin remained well at 18 months of age with no evidence of arterial calcification.

Spontaneous regression of calcification at eighteen months of age treatment was described in a case presented by Sholler et al. in 1984 [32]. The calcification disappeared completely by five years of age. Nine further cases of spontaneous resolution without diphosphonate treatment have been described since [7, 19, 32, 43-45]. The longest survivor was reported to be 22 years after spontaneous resolution [43].

\section{Conclusions}

This case series highlights the high mortality of IIAC, consistent with the literature, the clinical and genetic heterogeneity of the condition even within the same family and the vital role of prenatal diagnosis in case management. If there is a history of IIAC in an index pregnancy serial early fetal echocardiograms in a subsequent pregnancy may aid earlier prenatal diagnosis of this condition in order to plan appropriate care. Hyperechogenicity of mitral or tricuspid valves or vessel walls on prenatal ultrasound should prompt referral to fetal cardiology so that appropriate prenatal genetic counseling and molecular genetic testing for IIAC can occur. Early prenatal diagnosis of this condition will facilitate earlier commencement of biphosphonate therapy in the immediate neonatal period. More prenatal cases of biphosphonate therapy are needed to elucidate whether resolution or improvement in arterial calcification is due to the biphosphonate therapy or the milder phenotype of the disease. Our in-utero case of prenatal biphosphonate therapy highlights the potential important future role of this prenatal treatment in helping to reduce in-utero arterial calcification.

\section{Abbreviations}

ARHR type 2: Autosomal recessive hypophosphatemic rickets type 2; CVS: Chorionic villus sampling; ENPP 1: Ectonucleotide pyrophosphatase /phosphodiesterase 1; GACl: Generalized infantile arterial calcification; IACI: Idiopathic arterial calcification of infancy (IACI); IIAC: Idiopathic infantile arterial calcification; PPi: Inorganic pyrophosphate

\section{Acknowledgements}

Not applicable.

\section{Funding}

No funding was received.

\section{Availability of data and materials}

Data sharing not applicable to this article.

\section{Author's contributions}

All authors helped to draft the manuscript and approved the final manuscript.
Ethics approval and consent to participate

Within our centre, prospective general consent is obtained from patients booking for antenatal care for inclusion of data for research purposes, hence additional consent was not obtained. No research was performed on human or animal subjects. No identifying information is presented in this case series.

\section{Consent for publication}

Not applicable.

\section{Competing interests}

The authors declare that they have no competing interests.

This case series was presented as an oral poster presentation at ISUOG Rome sept 2016.

\section{Publisher's Note}

Springer Nature remains neutral with regard to jurisdictional claims in published maps and institutional affiliations.

\section{Author details}

${ }^{1}$ Fetal Medicine Unit, National Maternity Hospital, Holles St, D2, Dublin, Ireland. ${ }^{2}$ UCD Obstetrics and Gynaecology, School of Medicine, University College Dublin, Dublin, Ireland. ${ }^{3}$ Pathology Department, National Maternity Hospital, Dublin, Ireland. ${ }^{4}$ Paediatric Cardiology, Our Lady's' Hospital for Sick Children, Dublin, Ireland.

Received: 24 August 2018 Accepted: 28 December 2018

Published online: 23 January 2019

\section{References}

1. Stella J, Buers I, van de Wetering K, Höhne W, Rutsch F, Nitschke Y. Effects of different variants in the ENPP1 gene on the functional properties of Ectonucleotide pyrophosphatase/phosphodiesterase family member 1. Hum Mut. 2016:37:1190-201.

2. Rutsch F, Böyer $P$, Nitschke $Y$, the GACl Study Group, et al. Hypophosphatemia, hyperphosphaturia, and bisphosphonate treatment are associated with survival beyond infancy in generalized arterial calcification of infancy. Circ Cardiovasc Genet. 2008;1:133-40.

3. Glatz AC, Pawel BR, Hsu DT, Weinberg P, Chrisant MRK. Idiopathic infantile arterial calcification: two case reports, a review of the literature and a role for cardiac transplantation. Pediatr Transplant. 2006;10:225-33.

4. Bryant $\mathrm{JH}$, White WA. A case of calcification of the arteries and obliterative endarteritis associated with hydronephrosis in a child aged 6 months. Guys Hosp Rep. 1901;55:17-28.

5. Mastrolia SA, Weintraub AY, Baron J, Sciaky-Tamir Y, Koifman A, Loverro G, et al. Antenatal diagnosis of idiopathic arterial calcification: a systematic review with a report of two cases. Arch Gynecol Obstet. 2015;291:977-86.

6. Samyn MM, Bick D, Humphrey JA, Gandy KL. Successful congenital heart surgery for a toddler with idiopathic infantile arterial calcification. Paed Card. 2010;31:1096-9.

7. Gleason MM, Weber HS, Cyran SE, Baylen BG, Myers JL. Idiopathic infantile arterial calcinosis: intermediate-term survival and cardiac sequelae. Am Heart J. 1994;127:691-5.

8. Stuart G, Wren C, Bain H. Idiopathic infantile arterial calcification in two siblings: failure of treatment with diphosphonate. Br Heart J. 1990;64:156-9.

9. Nasrallah FK, Baho H, Sallout A, Qurashi M. Prenatal diagnosis of idiopathic infantile arterial calcification with hydrops fetalis. Ultrasound Obstet Gynecol. 2009;34:601-4.

10. Corbacioglu Esmer A, Kalelioglu I, Omeroglu RE, Kayserili H, Gulluoglu M, Has $R$, et al. Prenatal ultrasonographic diagnosis of generalized arterial calcification of infancy. J Clin Ultrasound. 2015;43:50-4.

11. Dlamini N, Splitt M, Durkan A, Siddiqui A, Padayachee S, Hobbins S, et al. Generalized Arterial Calcification of Infancy: Phenotypic spectrum among three siblings including one case without obvious arterial calcifications. Am J Med Genet. 2009:Part A 149A:456-60.

12. Spear R, Mack LA, Benedetti TJ, Cole RE. Idiopathic infantile arterial calcification. In utero diagnosis. J Ultrasound Med. 1990;9:473-6.

13. Crade M, Lewis DF, Nageotte MP. In utero appearance of idiopathic infantile arterial calcification:ultrasound study of a 28-week fetus. Ultrasound Obstet Gynecol. 1991;1:284-5. 
14. Samon LM, Ash KM, Murdison KA. Aorto-pulmonary calcification:an unusual manifestation of idiopathic calcification of infancy evident antenatally. Obstet Gynecol. 1995;85:863-5.

15. Eronen M, Pohjavuori M, Heikkila P. Fetal outcome of two siblings with idiopathic arterial calcification of infancy diagnosed in utero. Pediatr Cardiol. 2001:22:167-9.

16. Levine JC, Campbell J, Nadel A. Image in cardiovascular medicine. Prenatal diagnosis of idiopathic infantile arterial calcification. Circulation. 2001;103:325-6.

17. Nagar AM, Hanchate V, Tandon A, Thakkar H, Chaubal NG. Antenatal detection of idiopathic arterial calcification with hydrops fetalis. J Ultrasound Med. 2003;22:653-9.

18. Sundaram S, Kuruvilla S, Thirupuram S. Idiopathic arterial calcification of infancy- a case report. Images Paediatr Cardiol. 2004;6:6-12.

19. Ciana G, Trappan A, Bembi B, Benettoni A, Maso G, Zennaro F, et al. Generalized arterial calcification of infancy: two siblings with prolonged survival. Eur J Pediatr. 2006:165:258-63.

20. Kutty S, Cava JR, Frommelt MA. Idiopathic infantile arterial calcification: a case report of prenatal and postnatal echocardiographic diagnosis. Echocardiography. 2009;26:862-4.

21. Cansu A, Ahmetoglu A, Mutlu M, Guven S, Osmanagaoglu MA. Clin Exp Obstet Gynecol 2010; 37:73-75. Idiopathic infantile arterial calcification: prenatal diagnosis and postnatal presentation. Clin Exp Obstet Gynecol 37:73-75

22. Reitter A, Fischer D, Buxmann $H$, Nitschke $Y$, Rutsch F, Mottok $A$, et al Fetal hydrops, hyperechogenic arteries and pathological doppler findings at 29 weeks: prenatal presentation of generalized arterial calcification of infancy - a novel mutation in ENPP 1. Fetal Diagn Ther 2009;25:264-8. https://doi.org/10.1159/000223683 Epub 2009 Jun 10.

23. Nagaraj BR, Jain P, Thomas DA, Raghu M. Sonological appearance of idiopathic arterial calcification in fetus: a rare case. Indian J of Radiol Imaging. 2009;19:248-51.

24. Heuser CC, Puchalski M, Kennedy A, Sangle N, Manuck T, Andres R. Radiographic and pathologic evaluation of idiopathic infantile arterial calcification. Obstet Gynecol. 2010;115:465-8.

25. Wax JR, Blackstone J, Pinette MG, Cartin A. Hepatic vascular calcification;an early second trimester sonographic feature of idiopathic infantile arterial calcinosis. Am J Obstet Gynaecol. 2001;185:1267-8.

26. Gowda M, Papa D, Sagili H. Prenatal diagnosis of idiopathic infantile arterial calcification: a lethal heritable condition. Austin J Clin Case Rep. 2016:3:1086.

27. Pala HG, Bilgili G, Ulkumen BA, Alkan F, Coskun S. A case of antenatal diagnosis and postnatal characteristics of idiopathic infantile arterial calcification (IIAC and prenatal diagnosis). J Obstet Gynaecol. 2016;36:665-7.

28. Votava-Smith JK, Pitukcheewanont P, Randolph LM, Chmait RH. Generalized arterial calcification in a recipient twin:discordant fetal hemodynamics result in differing phenotypes in monozygotic twins with an ABCC6 mutation. Fetal Diagn Ther. 2017:41:234-6.

29. Rao U, Rani H, Rao R, Dinesh U, Ramamurthy B. Idiopathic infantile arterial calcification with thrombotic microangiopathy-a unique case. Fetal and Ped Pathology. 2010;29:413-8.

30. Agrawal G, Chintala K. Antenatal diagnosis of idiopathic arterial calcification with hydrops fetalis. Eur Heart J Cardiovasc Imaging. 2015;16:816.

31. Yi $Y$, Tong $T$, Liu $T$, Lin $Q$, Xiong $Y, X u$ J. Prenatal diagnosis of idiopathic infantile arterial calcification without fetal hydrops. Echocardiography. 2017; 34:311-4.

32. Sholler GF, Yu JS, Bale PM, Hawker RE, Celermajer JM, Kozlowski K Generalized arterial calcification of infancy: three case reports, including spontaneous regression with long-term survival. J Pediatr. 1984;105:257-60.

33. Prior JT, Bergstrom WW. Generalized arterial calcification in infants. Am J Dis Child. 1948;76:91-101.

34. Jones DED, Pritchard Kl, Gioannini CA, Moore DT, Bradford WD. Hydrops Fetalis associated with idiopathic arterial calcification. Obstet Gynecol. 1972; 39:435-40.

35. Juul S, Ledbetter D, Wright TN, Woodrum D. New insights into idiopathic infantile arterial calcinosis: three patient reports. Am J Dis Child. 1990;144: 229-33.

36. Galetti S, Nitschke Y, Malavolti AM, Aquilano G, Faldella G, Corvaglia L et al. Generalized arterial calcification of infancy:fetal clinical course associated with a novel mutation in ENPP1. JIMD Rep. 2011;1:23-27.

37. Levy-Litan V, Hershkovitz E, Avizov L, Leventhal N, Bercovich D, ChalifaCaspi $V$, et al. Autosomal-recessive Hypophosphatemic rickets is associated with an inactivation mutation in the ENPP1 gene. Am J Human Genet. 2010:86:273-8.

38. Guimaraes S, Lopes JM, Oliveira JB, Santos A. Idiopathic Infantile Arterial Calcification: A rare cause of sudden unexpected death in childhood. Patholog Res. 2010;Int:185314. https://doi.org/10.4061/2010/185314.

39. Sebire NJ, Ramsay A, Sheppard M. Idiopathic arterial calcification presenting with cardiac failure and sudden death in an eleven year old girl. Pediatr Dev Pathol. 2002;5:412-4.

40. Rutsch F, Schauerte P, Kalhoff H, Petrarulo M, August C, Diekmann L. Low levels of urinary inorganic pyrophosphate indicating systemic pyrophosphate deficiency in a boy with idiopathic infantile arterial calcification. Acta Paediatr. 2000;88:1265-9.

41. Van der Sluis IM, Boot AM, Vernooij M, Meradji M, Kroon AA. Idiopathic infantile arterial calcification: clinical presentation, therapy and long-term follow-up. Eur J Pediatr. 2006:165:590-3.

42. Patel M, Andronikou S, Solomon R, Sinclair P, McCulloch M. Idiopathic arterial calcification in childhood. Pediatr Radiol. 2004;34:652-5.

43. Marrott PK, Newcombe KD, Becroft DMO, Friedlander DH. Idiopathic infantile arterial calcification with survival to adult life. Pediatr Cardiol. 1984; 5:119-22.

44. Meradji M, De Villeneuve VH, Huber J, De Bruijn WC, Pearse RG. Idiopathic infantile arterial calcification in siblings: radiological diagnosis and successful treatment. J Pediatr. 1978;92:401-5

45. Van Dyck M, Proesmans W, Van Hollebeke E, Marchal G, Moerman P. Idiopathic infantile arterial calcification with cardiac, renal and central nervous involvement. Eur J Pediatr. 1989;148:374-7.
Ready to submit your research? Choose BMC and benefit from:

- fast, convenient online submission

- thorough peer review by experienced researchers in your field

- rapid publication on acceptance

- support for research data, including large and complex data types

- gold Open Access which fosters wider collaboration and increased citations

- maximum visibility for your research: over $100 \mathrm{M}$ website views per year

At $\mathrm{BMC}$, research is always in progress.

Learn more biomedcentral.com/submissions 